\title{
A Study on the Relationship among Resident Saving, Economic Growth, Monetary Policy and Stock Trading Volume in China ${ }^{1}$
}

\author{
Yunlong Shao ${ }^{1, \text { a }}$, Chenglei Dai ${ }^{1, \mathrm{~b}}$, Chongchong Lin $^{1}$, Jing Zhu, Wenhao Kang ${ }^{1}$ \\ and Pan Sun ${ }^{1}$ \\ ${ }^{1}$ Faculty of Science, Zhejiang University of Science and Technology, China \\ asyl_william@163.com and ${ }^{\mathrm{b}}$ daichenglei99@126.com
}

Key words: Resident Savings, Economic Growth, Stock Trading Volume, Monetary Policy, Vector Auto-Regression (VAR)

\begin{abstract}
The development of the stock market has close ties to the country's economy, the savings and the monetary policy, the relationships among four of them are still attracting a lot of researchers' attention. We use the Vector Auto Regressive approach to made empirical analysis on those. We have found that there exists a long-term equilibrium relationship among them. Stock trading volume growth of $41 \%$ is depending on resident savings, economic growth and monetary policy, but the development of the stock market itself to turnover rates remain at around 59\%.
\end{abstract}

\section{Introduction}

In the short term, China's stock market is difficult to reflect the situation of China's economy. In the long run, STV (stock trading volume), EG (economic growth) and RS (resident savings) is intertwined. Meantime, there is a positive relationship between MS (money supply) and STV.

Nowadays, at home and abroad, many scholars carried on an empirical research among them. Yuzhen Chen [1] concluded STV affects the changes of RS, however, the influence is nonsignificant. Effect of the distributary of stock market on RS is not obvious. By means of the VAR model and impulse response function, Mengmeng Kang [2] suggested that $80 \%$ of the shares traded growth depends on EG and RS. Wei Wang and Shigui Tao [3] pointed out that there is a certain correlation between stock index and China's monetary policy. Besides, in the abroad study of stock price and monetary policy [4], they pay more attention to monetary policy transmission mechanism of stock market. There are famous Tobin's Q theory, wealth effect channel, balance sheet channel and liquidity channel.

As can be seen from the existing research, Scholars have a divergence on the stock market, EG and RS; it's quite lacking in the empirical study which is to know the interactive relationship of stock market, EG, monetary policy, and RS.

\section{The Empirical Analysis}

This paper makes an empirical test using the data of Chinese economy quarterly from 1996 to 2012, which is acquired by China Statistical Yearbook and the people's bank of China website. We regard the money supply M2 as the index of money policy and GDP represents the economic growth. For eliminating the impact of heteroscedasticity, we changed the original data into logarithmic, then named LNGT,LNGDP,LNSD and LNMS, which respectively mean STV, GDP, RS and MS.

\section{Johansen Co-integration test of variables}

First, we must make stability analysis to each variable for ensuring that the result is unbiased and effective through ADF. As for variables LNGDP, LNSD and LNMS, the assumption of unit root testing can't be refused. In other words, they are non-stationary series. However, the four variables obey the process of I(1), for their lag-1 differencing series can reject the unit root hypothesis at $5 \%$

${ }^{1}$ Supported by Program of “Xinmiao” (Potential) Talents in Zhejiang Province (No.2012R415029) 
significance level. The variables all fill the qualification of co-integration testing that the time series used must pass the unit root testing with same lag. The following is the result of the test.

Table 1 The result of Johansen Co-integration Test

\begin{tabular}{|c|c|c|c|c|}
\hline $\begin{array}{c}\text { Hypothesized } \\
\text { No. of CE(s) }\end{array}$ & Eigenvalue & $\begin{array}{c}\text { Trace } \\
\text { Statistic }\end{array}$ & $\begin{array}{c}0.05 \\
\text { Critical Value }\end{array}$ & Prob.** \\
\hline None $*$ & 0.378269 & 70.486730 & 55.245784 & 0.001313 \\
\hline At most 1 $*$ & 0.321641 & 40.546127 & 35.010899 & 0.011620 \\
\hline At most 2 & 0.128270 & 16.097177 & 18.397715 & 0.101914 \\
\hline At most 3 $*$ & 0.111512 & 7.448753 & 3.841466 & 0.006345 \\
\hline
\end{tabular}

From the Table 1, not only co-integration hypothesis are rejected at 5\% significance level but also two co-integration relationship existed. It shows there is a long-run equilibrium relationship among STV, GDP, RS and MS.

\section{Estimation and Examine of VAR Model}

VAR is one of the easiest models that used to make analysis and prediction for more than one related economic indexes [5]. This paper adopts Lag Length Criteria to select lag length. As a result, we thought 6 is the greatest lag to model. In addition, reciprocal values of the roots of the characteristic equation are concentrated in the unit circle or on the unit circle, so the established model at lag 6 is available.

Through discussing the lead relations of variables between, Granger's causality tests analyze the direction of interaction among STV, GDP, RS and MS and determine the predictors of another three indexes to STV. In order to solve the problem that Granger's causality test is greatly sensitive to lag, under the guideline of AIC and SIC, the article gets the greatest lag of VAR is 6, cooperating the assistant of Maximum likelihood ratio statistic LR, Ljung2 Box Q statistics of the residuals and Jarque-Bera statistic test. The examination's consequence to sample series shows that with 5\% significance level, GDP and RS both are the Granger's reason of STV, while STV is the Granger's reason of RS and MS. Similarly, GDP relies on MS.

\section{Variables' effect of impact analysis}

As the result of co-integration test, despite the long-run equilibrium relations, it cannot show out the dynamic characteristics of model in a short term. The impulse function is used to describe the variables' track in the future or past when they meet a standard deviation shock of random disturbance term, directly depicting the dynamic interaction and effect among the variables. With examining, we conclude that it is reliable of VAR model with lag 6 that consist of four endogenous variables.
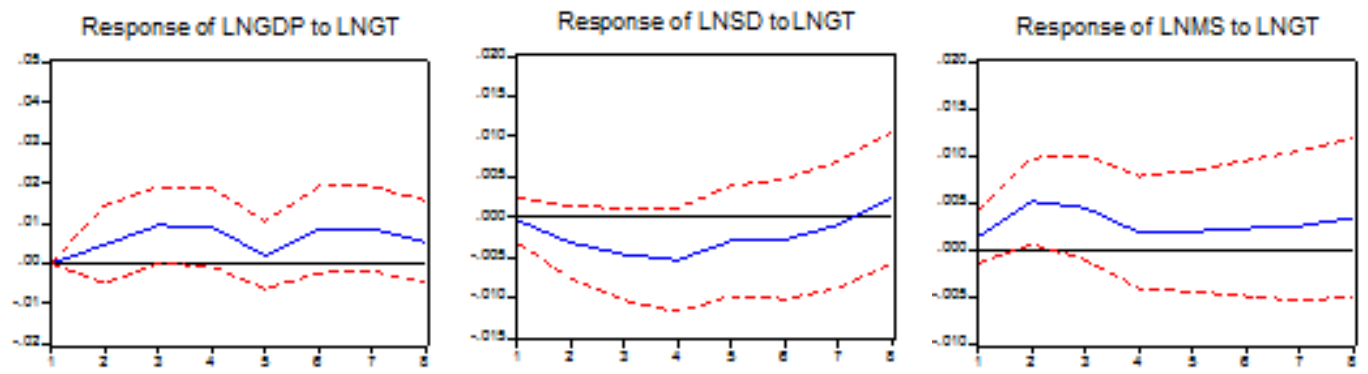

Fig. 1 The impulse function of endogenous variables

The following focus on analyzing the other three variables' effect to STV. The horizontal axis of the chart represents lag (unit: quarter), and the vertical axis represents STV. Besides, the full line represents the impulse function, revealing impact response of GDP and RS to STV, while the dotted line represents plus or minus two times the standard deviation zone. From this, there is a positive response between LNGT and LNGDP' s standard deviation shock, and it would last 15 months around, because of the pulse effect. Differently, as a standard deviation shock of LNSD to LNGT, it will reach a negative response right away and keep increasing. Due to several factors, this response turns to positive. But all in all, the effect of LNSD to LNGT is negative in the long-term. For LNMS, LNMS makes a positive response to LNGT, and converges to a stable value after 4 periods. 
Yet, the maximum of response is only 0.005 , lower relatively, which shows this effect isn't very notable.

\section{Variance Decomposition}

Be different from Impulse Response Function, variance decomposition pay more attention to evaluate the importance of different structural impact by contribution (usually measured by variance), which this article used to offer information on the relative importance of every stochastic disturbance's influence upon VAR variables, and evaluate economic growth, saving deposits and MS's contribution to STV. As we can know from Fig 2, GDP's contribution to STV can reach as much as $13.3 \%$ and it is not stable. It is $11.2 \%$ in stage 14 (quarter). Saving deposits' contribution to STV can be as much as $19.8 \%$ and MS about $10 \%$. This three factors' finally influence on STV is stable. Therefore, they have a co-integration relationship. That is to say, these four variables have a long-run equilibrium relationship while STV's own influence is as stable as 59\% or so.

MS exerts greatest influence on household savings while STV can contribute as much as $18 \%$ to MS. From this we can conclude that present Chinese stock market has little effect on household savings distribution. It is thought that the development of Chinese financial market is unsound due to these factors: a period of about 20 years' stock market development is short; And since China entered WTO in 2001, capital structure and violation operation problems still existed in public companies; Besides, Administrative mechanism problems are waiting to be sorted out.
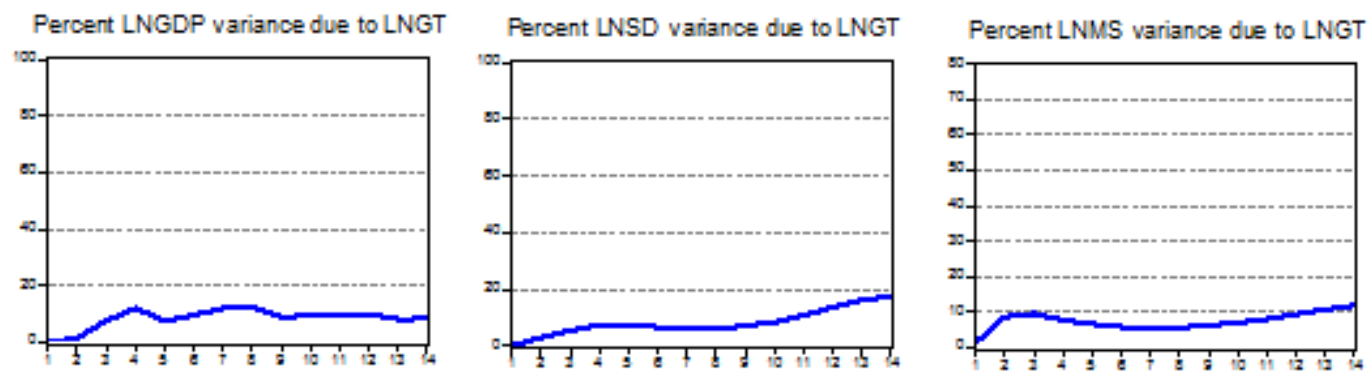

Fig. 2 The decomposition graph of Variance

\section{Summary}

This paper analyzes interactive relationship of stock trading volume, economic growth, resident savings, money supply (M2) by introducing the VAR model and then there are some following conclusions. Firstly, there is a co-integration relationship (a long-term equilibrium relationship) among stock trading volume, GDP, resident savings, and money supply. Secondly, according to the analysis of impulse response function, GDP have a positive response for stock trading volume and it would last 15 months around. However, resident savings and money supply have a negative response for stock trading volume, the effect is limited. Thirdly, from the variance decomposition, about $41 \%$ stock trading volume growth relies on economic growth, resident savings and money supply, which suggests that it does not have a dominant advantage in Shanghai and Shenzhen stock exchanges. Finally, resident stock investment preference is gradually enhanced, savings has been diverted into the stock market, and economic growth has attracted large amounts of money into Shanghai and Shenzhen stock market trading.

\section{References}

[1] Yuzhen Chen, Zhengnan Lu. Analysis of VAR model of China's stock market trading volume and the savings deposits of resident. Statistics and Decision. (2) 2005, 15-16.

[2] Mengmeng Kang. The interactive relationship of economic growth, resident saving and stock trading volume. Statistical Think tank. (1) 2009, 14-17.

[3] Wei Wang, Shi-gui Tao. An empirical research on stock market and monetary policy in China: the analysis based on VAR model. Journal of Nanjing University of Posts and Telecommunications (Social Science). (2) 2011, 39-46. 
[4] Frederic S.Mishkin. Monetary finance. Beijing: China Renmin University Press. 2006, p. 610-624.

[5] Tiemei Gao. Econometric analysis and modeling: Eviews application and instance Beijing: Tsinghua University Press. 2006, p.249-268. 